\title{
Aliskiren: A New Harbinger of Hypotension?
}

\author{
Elliot I. Palmer ${ }^{1}$, Andrew Oken ${ }^{1,2}$ \\ ${ }^{1}$ Oregon Health \& Science University (OHSU), Portland, USA; ${ }^{2}$ Veterans Affairs Medical Center (VAMC), Portland, USA. \\ Email: palmeell@ohsu.edu
}

Received January 23 ${ }^{\text {rd }}, 2013$; revised February $27^{\text {th }}, 2013$; accepted March $11^{\text {th }}, 2013$

\begin{abstract}
We present a case of significant, persistent, and relatively refractory hypotension during general anesthesia in a reasonably healthy 50 -year-old man thought to be caused by a direct rennin inhibitor. This case is of particular significance because the medication thought responsible for the hemodynamic abnormalities is a relatively novel antihypertensive agent and remains largely unknown to clinical anesthesia providers.
\end{abstract}

Keywords: Aliskiren; Renin Inhibitor; ACE Inhibitor; Hypotension; Anesthesia

\section{Introduction}

The literature concerning intra- and peri-operative management of patients taking ACE inhibitors and ARBs is plentiful, and includes many case reports, articles, and reviews; however, very little is currently written in these areas with respect to patients taking direct rennin inhibitors. We present a case of significant, persistent, and relatively refractory hypotension during general anesthesia in a reasonably healthy 50 -year-old man thought to be caused by a fairly novel antihypertensive agent. This case is of particular significance because the medication thought responsible for the hemodynamic abnormalities is relatively new and largely unknown to clinical anesthesia providers. Additionally, this medication is rapidly gaining popularity as a preferred treatment for both hypertension and diabetic nephropathy.

\section{Case Report}

A 50-year-old man with cervical radiculopathy presented for outpatient ACDF. He had a medical history significant for hypertension, hyperlipidemia, AODM, GERD, and osteoarthritis. He reported good preoperative exercise tolerance and specifically denied any history of cardiopulmonary disease. His medication list consisted of ibuprofen, metformin, omeprazole, rosuvastatin, aliskiren + valsartan, and aspirin. The only medication taken on the day of surgery was Omeprazole and our patient had been npo for 8 hours as instructed.

General Anesthesia was induced with fentanyl $2 \mathrm{mcg} /$ $\mathrm{kg}$ followed by Propofol $1.3 \mathrm{mg} / \mathrm{kg}$. Endotracheal intubation was facilitated with rocuronium $0.5 \mathrm{mg} / \mathrm{kg}$ and anesthesia was maintained with sevofluorane in oxygen. Immediately following induction, the patient developed hypotension that did not respond as expected to bolus doses of IV fluids (1.5 L LR), phenylephrine, epinephrine, and vasopressin and that was not corrected by surgical stimulation. During this period the ECG was unchanged, breath sounds were clear and bilateral, and airway pressures remained normal. There were no clinical signs to suggest significant hypovolemia, cardiac dysfunction, or an anaphylactic or anaphylactoid reaction. The patient did have a history of AODM, but not of any sequelae or complications of that disease that might suggest autonomic insufficiency as an etiology. The patient was maintained on $~ 0.6$ MAC sevoflurane in oxygen throughout the surgery. There was no notable blood loss. Throughout the 2.5 hour anesthetic, the patient received $2000 \mathrm{mcg}$ of phenylephrine, $50 \mathrm{mcg}$ of epinephrine, and 5 units of vasopressin in bolus doses along with continuous infusions of epinephrine $(0.2 \mathrm{mcg} / \mathrm{kg} / \mathrm{min})$ and phenylephrine $(0.8 \mathrm{mcg} / \mathrm{kg} / \mathrm{min})$ to maintain a MAP > 55 $\mathrm{mmHg}$. At the conclusion of the operative procedure, emergence from general anesthesia resulted in a prompt and sustained correction of the patient's hemodynamic disturbance. He required no further treatment in the PACU and was discharged home as planned.

\section{Discussion}

While the etiology of post-induction hypotension is often not entirely clear and inevitably involves a myriad of factors, we feel that the most likely etiologies were either promptly treated or eliminated from the differential. Furthermore, our treatments-which far exceeded the usual required doses-still did not produce the magnitude of change expected of them. We therefore hypothesize that the hemodynamic disturbances seen were largely a result of one of our patients' medications, the combination pill 
aliskiren + valsartan. Aliskiren (trade names Tekturna and Rasilez) is a direct renin inhibitor and is the first drug in its class. It has been FDA approved since 2007 [1] and is quickly gaining popularity among prescribing physicians. By binding directly to rennin, Aliskiren blocks the activation of the RAAS at the initial and rate-limiting step [2]. This inactivation of renin prevents the conversion of angiotensinogen to angiotensin and by doing so inhibits the generation of the potent vasoconstrictor angiotensin II as well as inhibiting the other hemodynamic consequences of circulating angiotensin II.

ACE inhibitor and ARB - associated hypotension under general anesthesia is now a well described phenomenon [3-7]. Though the exact mechanism of this association is not clearly known, it can be assumed that the direct rennin inhibitor Aliskiren, acting earlier on the same pathway and producing similar if not more exaggerated downstream effects, would have similar anesthetic implications-our experience seems to validate that assumption.

Our experience is particularly important for two additional reasons: First, aliskiren is a relatively foreign entity to practicing anesthesiologists. A Pubmed/MEDLINE search for "aliskiren" or "Tekturna" and "anesthesia" yielded only a single result discussing guidelines for withholding drugs that act on the RAAS prior to general anesthesia [8]. To our knowledge there are no previously described cases of Aliskiren-associated hypotension under general anesthesia. Furthermore, a casual survey of both staff and resident anesthesiologists at our institutions revealed widespread naiveté regarding Aliskiren: most did not realize that such a drug existed. Second, the unique pharmacokinetics of aliskiren have notable clinical implications: Different sources quote half life of aliskiren anywhere from 24 - 40 hours [9-11]. Many institutions, including ours, currently instruct patients to discontinue angiotensin converting enzyme inhibitors and angiotensin receptor antagonists 24 hours prior to surgery and general anesthesia. Though no national guidelines exist, this recommendation is in part based on the known half-lives of these medications, which range from 10 - 12 hours for ACE inhibitors and 2 - 6 hours for ARBs. If the same prophylactic prohibition was placed on Aliskiren, it might require 3 - 5 days of drug abstinence to be effective.

Our report is of a single episode of exaggerated hypotension with no identifiable cause other than Aliskiren. More experience is needed before drawing definite conclusions and certainly before any change of practice is advocated. If nothing else though, this report is intended to increase awareness of a new medication that is undoubtedly increasing in prevalence on the medication lists of our patients. It is also intended to serve as a clinical case report/alert regarding this relatively new medi- cation in the context of general anesthesia.

\section{REFERENCES}

[1] US Food and Drug Administration, "FDA News Release P07-38," 2011.

http://www.fda.gov/NewsEvents/Newsroom/PressAnnou ncements/2007/ucm108862.html

[2] M. Azizi, R. Webb, J. Nussberger and N. Hollenberg, "Renin Inhibition with Aliskiren: Where Are We Now, and Where Are We Going?” Journal of Hypertension, Vol. 24, No. 2, 2006, pp. 243-256. doi:10.1097/01.hjh.0000202812.72341.99

[3] P. Colson, J. Ribstein, A. Mimran, D. Grolleau, P. A. Chaptal and B. Roquefeuil, "Effect of Angiotensin-Converting Enzyme Inhibition on Blood Pressure and Renal Function during Open Heart Surgery,” Anesthesiology, Vol. 72, No. 1, 1990, pp. 23-27. doi:10.1097/00000542-199001000-00005

[4] A. P. Yates and D. N. Hunter, "Anaesthesia and Angiotensin-Converting Enzyme Inhibitors. The Effect of Enalapril on Perioperative Cardiovascular Stability," Anaesthesia, Vol. 43, No. 11, 1988, pp. 935-938. doi:10.1111/j.1365-2044.1988.tb05655.x

[5] S. Brabant, D. Eyraud, M. Bertrand and P. Coriat, "Refractory Hypotension after Induction of Anesthesia in a Patient Chronically Treated with Angiotens in Receptor Antagonists,” Anesthesia and Analgesia, Vol. 89, No. 4, 1999, pp. 887-888.

[6] P. Coriat, C. Richer, T. Douraki, C. Gomez, K. Hendricks, J.-F. Giudicelli and P. Viars, "Influence of Chronic Angiotensin-Converting Enzyme Inhibition on Anesthetic Induction,” Anesthesiology, Vol. 81, No. 2, 1994, pp. 299307. doi:10.1097/00000542-199408000-00006

[7] U. Thaker, V. Geary, P. Chalmers and F. Sheikh, "Low Systemic Vascular Resistance during Cardiac Surgery: Case Reports, Brief Review, and Management with Angiotensin II,” Journal of Cardiothoracic Anesthesia, Vol. 4, No. 3, 1990, pp. 360-363. doi:10.1016/0888-6296(90)90046-I

[8] M. Auron, B. Harte, A. Kumar and F. Michota, "ReninAngiotensin System Antagonists in the Perioperative Setting: Clinical Consequences and Recommendations for Practice,” Postgraduate Medical Journal, Vol. 87, No. 1029, 2011, pp. 472-481. doi:10.1136/pgmj.2010.112987

[9] Novartis Pharmaceuticals Corporation, “Tekturna ${ }^{\circledR}$ (Aliskiren) Tablets [Prescribing Information]. East Hanover (NJ)," 2009.

http://www.pharma.us.novartis.com/product/pi/pdf/tektur na.pdf

[10] Aliskiren (Drug Evaluation), “Drugdex System, MICROMEDEX Healthcare Series [Proprietary Database on the Internet]. Greenwood Village (CO): Thomson MICROMEDEX,” 2011.

[11] AHFS Drug Information, "Bethesda (MD): American Society of Health Systems Pharmacists,” 2011. 